\title{
Оценка потоков тяжелых металлов из атмосферы на поверхность Баренцева моря
}

\author{
Виноградова А.А. ${ }^{1}$, Котова Е.И. ${ }^{2}$ \\ ${ }^{1}$ Институт физики атмосферы им. А.М. Обухова РАН, Москва, anvinograd@yandex.ru \\ ${ }^{2}$ Федеральный исследовательский цеентр комплексного изучения Арктики им. акад. Н.П. Лаверова РАН, \\ Архангельск,есорр@yandex.ru
}

Аннотация. Выполнены оценки потоков антропогенных тяжелых металлов (TM) - Pb, Cd, As, $\mathrm{Zn}, \mathrm{Ni}$, $\mathrm{Cr}, \mathrm{Cu}$ - на поверхность Баренцева моря по рассчитанным ранее концентрациям этих элементов в приземной атмосфере в трех районах на побережье моря (Кольский полуостров, район Ненецкого заповедника, арх. Земля Франца-Иосифа). За счет большой площади, Баренцево море за год набирает из атмосферы больше всего антропогенных поллютантов - из всех российских северных морей, однако плотность потоков ТМ из атмосферы максимальна в Белом море. Для потоков свинца и кадмия по оценкам отчетов ЕМЕР сделаны поправки, учитывающие вклад выбросов ТМ с территории стран зарубежной Европы, а также вклад процессов ветрового поднятия пыли и почвенных частиц. Эти источники добавляют на всю территорию моря примерно $50 \%$ свинца и около 40 \% кадмия. В целом за год атмосфера поставляет лишь доли процентов ТМ, содержащихся в водах Баренцева моря. Весной в период таяния льдов атмосферный вклад в концентрации ТМ в воде моря может быть выше среднего в 2-10 раз, достигая для $\mathrm{Ni}$ и Сu нескольких процентов.

Ключевые слова: Баренцево море, антропогенное загрязнение, тяжелые металлы, дальний перенос в атмосфере, потоки из атмосферы на поверхность, вклад атмосферы в содержание ТМ в воде.

\section{Assessment of heavy metal fluxes from the atmosphere to the Barents Sea}

\author{
Vinogradova A.A. ${ }^{1}$, Kotova E.I. ${ }^{2}$ \\ ${ }^{I}$ A.M. Obukhov Institute of Atmospheric Physics RAS, Moscow, anvinograd@yandex.ru \\ ${ }^{2}$ N. Laverov Federal Center for Integrated Arctic Research RAS, Arkhangelsk, ecopp@yandex.ru
}

\begin{abstract}
The fluxes of anthropogenic heavy metals ( $\mathrm{HM})-\mathrm{Pb}, \mathrm{Cd}, \mathrm{As}, \mathrm{Zn}, \mathrm{Ni}, \mathrm{Cr}, \mathrm{Cu}-$ to the surface of the Barents Sea were estimated using previously calculated concentrations of these elements in the surface atmosphere at three points on the coast of the Sea (on the Kola Peninsula, in the region of Nenets Nature Reserve, at Franz-Josef Land archipelago). Due to the large surface, the Barents Sea yearly collects most of anthropogenic pollutants from the atmosphere - in comparison with other Russian northern seas. However, the White Sea water is most densely polluted by HM from the atmosphere. For the fluxes of lead and cadmium, according to the estimates of the EMEP reports, amendments have been made, taking into account the contribution of HM emissions from the territory of foreign Europe, as well as the contribution of wind-raising dust and soil particles. These sources add about $50 \%$ of lead and about $40 \%$ of cadmium to the entire sea. In general, the atmosphere annually supplies only a fraction of the percent of HM contained in the waters of the Barents Sea. In spring, during the ice-melting period, the atmospheric contributions to $\mathrm{HM}$ water concentrations may be 2-10 times higher than the average value, reaching several percent for $\mathrm{Ni}$ and $\mathrm{Cu}$.

Key words: Barents Sea, anthropogenic pollution, heavy metals, long-range atmospheric transport, fluxes from the atmosphere to the surface, contribution of the atmosphere to HMs' contents in the water
\end{abstract}

\section{Введение}

Арктика - регион Северного полушария, влияющий на климатическое равновесие в пределах всего Земного шара, удаленный от основных мест проживания и активности человека и все же подверженный антропогенному воздействию (Persistent, 2004). Состав вод морей формируется веществом, попадающим в воду в результате абразии берегов, приносимым водами морских и океанических течений и системы наземного стока, а также поступающим на поверхность моря из атмосферы. Микроэлементы и, в частности, тяжелые металлы (ТM) переносятся в атмосфере на аэрозольных частицах субмикронного размера на расстояния в несколько тысяч километров. В результате, даже для арктических территорий оказывается значимым вынос ТМ атмосферными потоками из районов их максимальных эмиссий в атмосферу (крупные города и промышленные комплексы средних и северных широт) (Barrie, 1986; Виноградова, 1993; АМАР, 1998; Виноградова, 2014). 
Сравнительные оценки вклада атмосферы и речного стока ТМ в содержание ТМ в водах морей Северного Ледовитого океана (СЛО) показывают, что в целом вклад атмосферы значительно меньше (Виноградова, Котова. 2019). В данной работе мы анализируем годовые потоки ТМ из атмосферы в воды Баренцева моря, сравниваем вклады Российских антропогенных источников и источников зарубежной Европы, делаем первые оценки эффекта весеннего таяния льда на содержание ТМ в морской воде.

\section{Постановка задачи, исходные данные}

В предыдущих публикациях авторов (Виноградова, Иванова, 2016; 2017) для трех пунктов, расположенных на побережье Баренцева моря (рис. 1), были оценены концентрации ряда аэрозольных составляющих антропогенного происхождения (ТМ) в приземном воздухе зимой и летом (табл. 1). Идея данной работы состоит в том, чтобы по этим разнесенным в пространстве данным оценить годовые потоки ТМ из атмосферы на поверхность моря и сравнить полученные оценки с имеющимися в литературе.

Рассматриваются семь микроэлементов ( $\mathrm{Pb}, \mathrm{Cd}, \mathrm{As}, \mathrm{Zn}, \mathrm{Ni}, \mathrm{Cr}, \mathrm{Cu})$, которые обычно условно называют ТМ. Исходные данные - это средние (за 2010-2015 гг.) концентрации ТМ в приземном воздухе, рассчитанные по массивам траекторий переноса воздушных масс к указанным на рис. 1 пунктам. Использовались данные об антропогенных эмиссиях ТМ на территории России за 2010 год из (Ежегодник..., 2011). Более свежие данные в достаточном объеме в литературе отсутствуют. Современная авторская методика оценок дальнего переноса воздушных масс и примесей на субмикронных аэрозолях подробно описана в (Виноградова, 2014).

ТМ антропогенного происхождения переносятся в атмосфере на дальние расстояния на субмикронных аэрозольных частицах, для которых время жизни в воздушных потоках составляет зимой до 10 суток, летом - около 3 суток, в зависимости от количества и интенсивности осадков. Зная концентрацию примеси в приземном воздухе $C$ и задавая скорости ее осаждения $K$ из атмосферы на поверхность для зимы и лета (численные значения этого параметра для разных регионов России

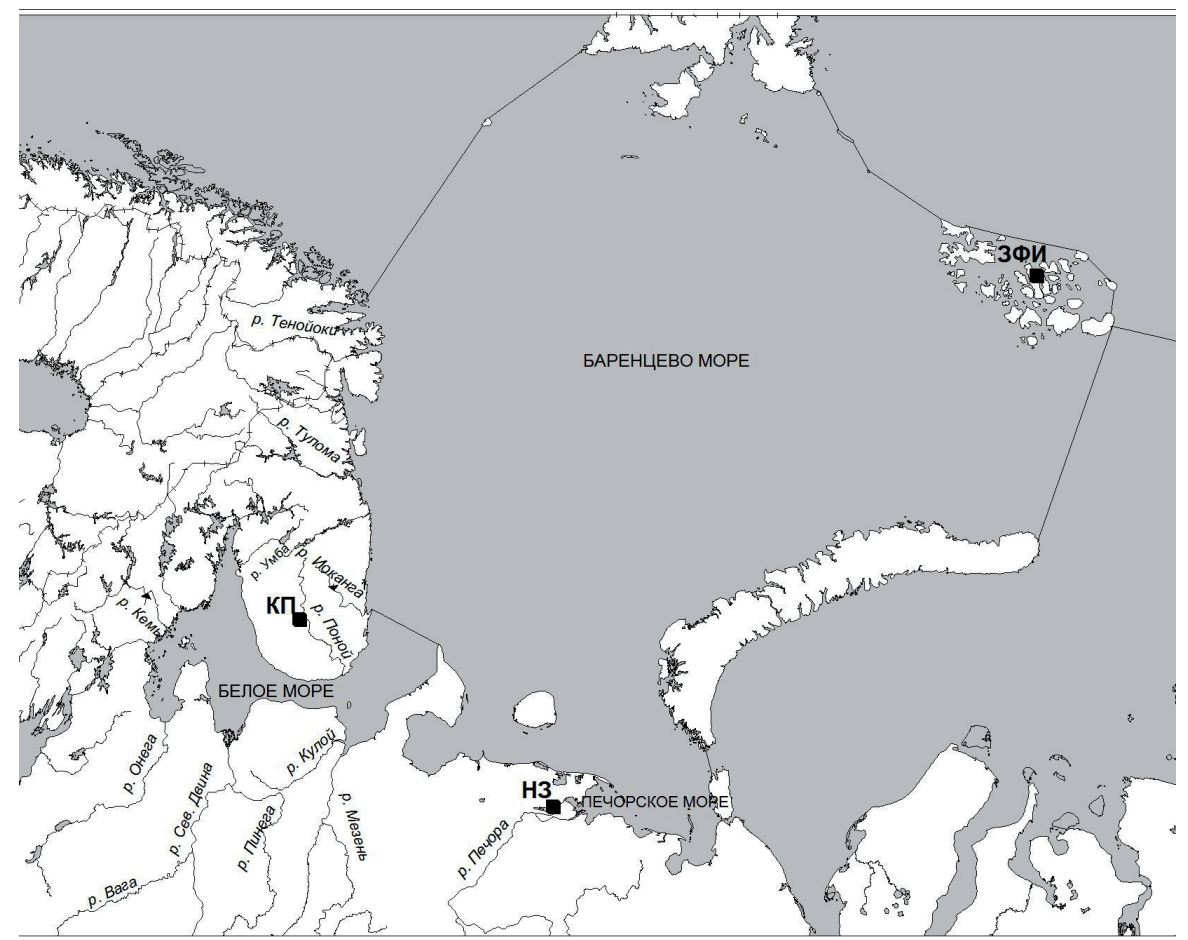

Рис. 1. Пункты с рассчитанными концентрациями ТМ в воздухе.

КП - на Кольском п-ове, НЗ - в Ненецком природном заповеднике, ЗФИ - на арх. Земля Франца-Иосифа.

Fig. 1. The points with previously calculated HM concentrations in air.

On Kola Peninsula, in the region of Nenets Nature Reserve, at Franz-Josef Land archipelago. 
приведены в (Виноградова, 2014)), вычисляем для зимы и лета плотность потоков $F$ рассматриваемых ТМ из атмосферы на подстилающую поверхность (на единицу площади) по формуле:

$$
\mathrm{F}=\mathrm{C} \times \mathrm{K} \times \mathrm{T},
$$

где $T$ - длительность периода (в данном случае один месяц). В наших вычислениях скорость осаждения не различалась по микроэлементам. Плотность потока примеси из атмосферы за год для пунктов КП и НЗ рассчитывалась в предположении равенства длительности летнего и зимнего сезонов, а для ЗФИ предполагалось 8 зимних месяцев и 2 летних.

Для одного и того же элемента зимняя и летняя концентрации в воздухе могут различаться на несколько порядков таблице 1. Это связано с различиями условий циркуляции атмосферы зимой и летом, с удаленностью в целом наиболее значимых источников загрязнений от побережья СЛО, а также с изменением количества и качества осадков в течение года. Кольский п-ов наиболее загрязнен свинцом, никелем и медью, т.е. элементами, которые в этом же регионе выбрасываются в атмосферу в огромных масштабах. Загрязнение этими ТМ убывает последовательно в пунктах НЗ и ЗФИ. Район НЗ больше, чем природа Кольского п-ова, загрязнен цинком и хромом (основные источники - промышленные районы Среднего Урала (Виноградова, Иванова, 2016; 2017)). В целом, наименее загрязнен удаленный пункт ЗФИ, расположенный на 10 градусов севернее двух других.

Таблица. 1. Исходные данные для оценок: концентрации ТМ в воздухе (нг/м³) зимой и летом, потоки ТМ из атмосферы на поверхность за год (кг/км²/год) вблизи трех пунктов (рис. 1), скорость осаждения $(K, \mathrm{~cm} / \mathrm{c})$.

Table 1. Basic data for calculations: HM concentrations in air $\left(\mathrm{ng} / \mathrm{m}^{3}\right)$ for winter and summer, annual HM fluxes onto the surface $\left(\mathrm{kg} / \mathrm{km}^{2} / \mathrm{yr}\right)$ near three points (fig. 1), deposition velocity $(K, \mathrm{~cm} / \mathrm{s})$.

\begin{tabular}{|c|c|c|c|c|c|c|c|c|c|c|}
\hline 莺 & Параметр & Срок & $\mathrm{Pb}$ & $\mathrm{Cd}$ & As & $\mathrm{Zn}$ & $\mathrm{Ni}$ & $\mathrm{Cr}$ & $\mathrm{Cu}$ & $\kappa$ \\
\hline \multirow{3}{*}{ КП } & \multirow{2}{*}{ Концентрация } & январь & 5.5 & 0.025 & 3.0 & 1.3 & 45 & 1.3 & 56 & 0.16 \\
\hline & & июль & 0.40 & 0.00075 & 0.20 & 0.0014 & 1.5 & 0.011 & 4.7 & 1.55 \\
\hline & $\Pi$ & год & 0.34 & 0.0033 & 0.12 & 0.033 & 1.5 & 0.036 & 2.5 & \\
\hline \multirow{3}{*}{ H3 } & \multirow{2}{*}{ Концентрация } & январь & 0.92 & 0.0971 & 1.3 & 7.6 & 4.8 & 1.2 & 9.5 & 0.09 \\
\hline & & июль & 0.0011 & 0.0000 & 0.0017 & 0.0012 & 0.37 & 0.00091 & 0.19 & 0.87 \\
\hline & Поток & год & 0.020 & 0.0034 & 0.019 & 0.11 & 0.12 & 0.016 & 0.16 & \\
\hline \multirow{3}{*}{ ЗФИ } & \multirow{2}{*}{ Концентрация } & январь & 0.058 & 0.00017 & 0.0057 & 0.014 & 1.5 & 0.0053 & 1.8 & 0.09 \\
\hline & & июль & 0.00011 & 0.000000003 & 0.00000003 & 0.0000016 & 0.0026 & 0.0000012 & 0.0025 & 0.2 \\
\hline & Поток & год & 0.0014 & 0.0000040 & 0.00013 & 0.00032 & 0.035 & 0.00012 & 0.042 & \\
\hline
\end{tabular}

\section{Подход к оценкам потоков ТМ из атмосферы на поверхность моря и результаты}

При удалении от источника поток примеси на поверхность обычно можно описать экспоненциальной зависимостью от расстояния. Качественно понятно, что при удалении от материка (с источниками ТМ) на север загрязнение атмосферы и потоки ТМ на поверхность должны уменьшаться. В данной работе при расчетах потоков ТМ из атмосферы на поверхность моря (ПМ) применялась методика, предложенная в (Виноградова, Котова, 2019).

В случае большой площади ПМ, когда на побережье есть хотя бы две точки $x_{1}$ и $x_{2}$, расположенные на границе моря на разных широтах, с известными величинами плотности потока ТМ $F_{l}$ и $F_{2}$ на поверхность, предполагается, что вдоль оси $x$, соединяющей эти точки, плотность потока ТМ из атмосферы на поверхность убывает экспоненциально $\mathrm{F}=\mathrm{Aexp}(-\mathrm{Bx})$, а в перпендикулярном направлении (в первом приближении) этот профиль не меняется.

Система уравнений

$$
\begin{aligned}
& \mathrm{F}_{1}=A \exp \left(-\mathrm{Bx}_{1}\right) \\
& \mathrm{F}_{2}=\operatorname{Aexp}\left(-\mathrm{Bx}_{2}\right)
\end{aligned}
$$


при введении $x_{1}=0 u x_{2}=L$, где $L$ - расстояние между точками $x_{1}$ и $x_{2}$, позволяет найти выражение для расчета потока ТМ на ПМ:

$$
\mathrm{D}=\left(\mathrm{F}_{1}-\mathrm{F}_{2}\right) / \ln \left(\mathrm{F}_{1} / \mathrm{F}_{2}\right) \times \mathrm{S}_{\text {Пм }} .
$$

Для расчетов по Баренцеву морю мысленно разбиваем его поверхность линиями, идущими с юга на север, на три равные по площади части (западную, центральную и восточную). На южных сторонах западной и восточной частей плотности годовых потоков ТМ принимаем равными величинам из табл. 1 для КП и НЗ, соответственно, на южной стороне центральной части - средним арифметическим значениям для этих пунктов. На северных границах везде плотности потоков ТМ соответствуют данным табл. 1 для ЗФИ. Результаты расчетов потоков ТМ из атмосферы на поверхность Баренцева моря по формулам (1)-(4) приведены в табл. 2. Видно, что больше всего ТМ из атмосферы поступает в воды западной части Баренцева моря, только цинком больше загрязнена восточная часть.

Таблица 2. Годовые потоки ТМ из атмосферы на поверхность Баренцева моря по частям (см. текст) и суммарно, т/год. Площадь моря 1424000 км². $^{2}$

Table 2. Annual HM fluxes from the atmosphere onto the surface of the Barents Sea partly (see text) and totally, $\mathrm{t} / \mathrm{yr}$. Sea square is $1424000 \mathrm{~km}^{2}$.

\begin{tabular}{|l|l|l|l|l|l|l|l|}
\hline Часть ПМ & $\mathrm{Pb}$ & $\mathrm{Cd}$ & $\mathrm{As}$ & $\mathrm{Zn}$ & $\mathrm{Ni}$ & $\mathrm{Cr}$ & $\mathrm{Cu}$ \\
\hline Запад & 29 & 0.23 & 8.6 & 3.4 & 184 & 3.0 & 287 \\
\hline Восток & 3.3 & 0.24 & 1.8 & 8.7 & 32 & 1.6 & 42 \\
\hline Середина & 17 & 0.23 & 5.4 & 6.1 & 117 & 2.3 & 178 \\
\hline Сумма & $\mathbf{5 0}$ & $\mathbf{0 . 7 0}$ & $\mathbf{1 6}$ & $\mathbf{1 8}$ & $\mathbf{3 3 3}$ & $\mathbf{6 . 9}$ & $\mathbf{5 0 7}$ \\
\hline
\end{tabular}

Можно сравнить уровни загрязнения ТМ по атмосферному каналу (табл. 3) для Баренцева моря и ещё трех северных морей России - из (Виноградова, Котова, 2019). Больше всех загрязняется Белое море, расположенное в окружении мощных производственных комплексов северо-запада России. Баренцево море, за счет своей большой площади, по этому показателю на втором месте.

Таблица 3. Средняя плотность потоков ТМ на единицу поверхности для Баренцева моря и трех других арктических морей России, кг $/ \mathrm{\kappa м}^{2} /$ год.

Table 3. Average HM fluxes from the atmosphere onto the unit surface for the Barents Sea and the other three Seas of the Russian Arctic, $\mathrm{kg} / \mathrm{km}^{2} / \mathrm{yr}$.

\begin{tabular}{|l|l|l|l|l|c|l|l|}
\hline \multicolumn{1}{|c|}{ Море } & \multicolumn{1}{c|}{$\mathrm{Pb}$} & \multicolumn{1}{c|}{$\mathrm{Cd}$} & \multicolumn{1}{c|}{$\mathrm{As}$} & \multicolumn{1}{c|}{$\mathrm{Zn}$} & $\mathrm{Ni}$ & \multicolumn{1}{c|}{$\mathrm{Cr}$} & \multicolumn{1}{c|}{$\mathrm{Cu}$} \\
\hline Баренцево & $\mathbf{0 . 0 3 5}$ & $\mathbf{0 . 0 0 0 4 9}$ & $\mathbf{0 . 0 1 1}$ & $\mathbf{0 . 0 1 3}$ & $\mathbf{0 . 2 3}$ & $\mathbf{0 . 0 0 4 8}$ & $\mathbf{0 . 3 6}$ \\
\hline Белое & 0.22 & 0.0040 & 0.083 & 0.18 & 0.80 & 0.13 & 1.4 \\
\hline Карское & 0.0085 & 0.00016 & 0.0013 & 0.0069 & 0.17 & 0.0012 & 0.17 \\
\hline Лаптевых & 0.0028 & 0.00004 & 0.00003 & 0.0001 & 0.06 & 0.00006 & 0.06 \\
\hline
\end{tabular}

\section{Комментарии и выводы}

ТМ в приземной атмосфере имеют не только антропогенное происхождение, но входят в состав терригенного вещества, и появляются в аэрозолях за счет ветрового поднятия и перевевания частиц почвы и пыли. На европейской территории России концентрации ТМ в воздухе ещё увеличиваются из-за трансграничного атмосферного переноса от источников стран зарубежной Европы. Значения годовых потоков $\mathrm{Pb}$ и $\mathrm{Cd}$, приведенные в таблицах 1-3, учитывают поправки за счет этих процессов (Travnikov et al., 2012; Ilyin et al., 2014; Виноградова, 2015; Виноградова, Котова, 2018), которые составили для $\mathrm{Pb}$ около 50 \% по всей ПМ, для $\mathrm{Cd}$ в среднем около $40 \%$, увеличиваясь с запада на восток от $35 \%$ до 45 \%. Для остальных ТМ нет данных, чтобы выполнить аналогичные оценки. Для них приведенные в таблицах оценки занижены, т.к. учитывают лишь антропогенные источники европейской России.

Считается, что воды сравнительно неглубокого (в среднем 200 м) Баренцева моря за зиму полностью перемешиваются за счет конвекции и обновляются течениями за 1-2 года (Ожигин и др., 2016). 
Предполагая, что выделенные три части моря равны не только по площади, но и по объему воды, было получено, что концентрации $\mathrm{Cd}, \mathrm{Ni}$ и $\mathrm{Cu}$, создаваемые в воде лишь атмосферными выпадениями, на несколько порядков ниже измеренных значений (Новиков, Драганов, 2017). Даже в местах наибольшего загрязнения из атмосферы (вблизи Кольского п-ова) роль атмосферного канала в загрязнении вод моря мала. Таким образом, микроэлементный состав основной массы вод Баренцева моря формируется водами Нордкапского течения, идущего с запада из Норвежского моря (Новиков, Драганов, 2017).

Сезонные вариации поступления и концентраций ТМ в водах Баренцева моря пока, видимо, не изучались. Весной, в период таяния льдов, в воды моря попадает все вещество, накопленное за зимний период во льду и в снеге на его поверхности. В это время вклад атмосферы в загрязнение поверхностной воды должен быть максимальным. Предположим, что время зимнего накопления примеси составляет полгода, поверхностный слой воды равен 20 м, а время таяния льда 1 мес. Используя январские оценки концентраций ТМ в воздухе рассматриваемых пунктов (табл. 1), получим, что в весенний месяц после таяния концентрации рассматриваемых ТМ в воде вблизи этих пунктов должны быть в 2-10 (среднее 8) раз выше, чем расчетные среднегодовые значения. В результате весной вблизи побережья Кольского п-ова возможно повышение вклада атмосферы в концентрации ТМ в морской воде до 4,5\% и $3.5 \%$ для $\mathrm{Ni}$ и $\mathrm{Cu}$, соответственно, - по сравнению со средними (по всему морю) измеренными величинами. Однако вблизи Кольского побережья и измеренные концентрации этих элементов тоже заметно выше средних, что можно считать следствием влияния поверхностного стока (Новиков, Драганов, 2017) и абразии берегов Кольского п-ова. Таким образом, относительный вклад атмосферного канала все равно будет невелик.

\section{Литература}

1. Виноградова А.А.. Микроэлементы в составе арктического аэрозоля (обзор) // Изв. АН. Физика атмосферы и океана. 1993. Т. 29. № 4. С. 437-456.

2. Виноградова А.А. Дистанционная оценка влияния загрязнения атмосферы на удаленные территории // Геофизические процессы и биосфера. 2014. Т. 13. № 4. С. 5-20.

3. Виноградова А.А. Потоки свинца и кадмия из атмосферы на поверхность на европейской территории России - по данным международной программы EMEP // Международный журнал прикладных и фундаментальных исследований. 2015. № 12. С. 111-115.

4. Виноградова А.А., Иванова Ю.А. Тяжелые металлы в атмосфере над северным побережьем Евразии: межгодовые вариации зимой и летом // Геофизические процессы и биосфера. 2016. Т. 15. № 4. С. 5-17.

5. Виноградова А.А., Иванова Ю.А. Перенос воздушных масс и загрязнений к арктическим островам России (1986-2016): долговременные, межгодовые и сезонные вариации // Геофизические процессы и биоcфера. 2017. T. 16, № 4. C. 5-20.

6. Виноградова А. А., Котова Е. И. Вклады источников Европы в загрязнение свинцом и кадмием северных районов Европейской России // Живые и биокосные системы. 2018. № 23. URL: http://www.jbks.ru/archive/ issue-23/article-2.

7. Виноградова А.А., Котова Е.И. Загрязнение северных морей России тяжёлыми металлами: поток из атмосферы и речной сток // Геофизические процессы и биосфера. 2019. Т. 18. № 1. В печати.

8. Ежегодник выбросов загрязняющих веществ в атмосферный воздух городов и регионов Российской Федерации за 2010 год. А.Ю. Недре. СПб: НИИ Атмосфера. 2011. 560 с.

9. Новиков М.А., Драганов Д.М. Комплексный методический подход к определению фоновых значений содержания микроэлементов в водных массах Баренцева моря на примере $\mathrm{Cd}, \mathrm{Co}, \mathrm{Cu}$ и $\mathrm{Ni} / / \mathrm{Bec}$ вник КРАУНЦ. Науки о Земле. 2017. Вып. 34. № 2. С. 37-48.

10. Ожигин В.К. и др. Воды Баренцева моря: структура, циркуляция, изменчивость. Мурманск: ПИНРО, 2016. $260 \mathrm{c}$.

11. AMAP Assessment report: Arctic pollution issues. Oslo, Norway: AMAP. 1998. 859 p.

12. Barrie L.A. Arctic air pollution: an overview of current knowledge // Atmos. Environ. 1986. V. 20. N 4. P. 643-663.

13. Ilyin I., et al. Heavy Metals: Transboundary Pollution of the Environment // EMEP Status Report 2/2014. MSC-E\&CCC. 2014. $71 \mathrm{p}$.

14. Persistent Toxic Substances, Food Security and Indigenous Peoples of the Russian North. Final Report. Oslo, Norway: AMAP. 2004. 192 p.

15. Travnikov O., et al. Long-term Changes of Heavy Metal Transboundary Pollution of the Environment (1990-2010) // EMEP Status Report 2/2012. 63 p. 